\title{
Sexually transmitted diseases in laboring women: trend over a decade
}

\author{
Kavita Mahadevappa*, Naveen Prasanna, Ramalingappa C. Antaratani
}

Department of Obstetrics and Gynaecology, Karnataka Institute of Medical Sciences, Hubli, India

Received: 06 January 2016

Accepted: 08 February 2016

*Correspondence:

Dr. Kavita Mahadevappa,

E-mail: kavipgi10@gmail.com

Copyright: () the author(s), publisher and licensee Medip Academy. This is an open-access article distributed under the terms of the Creative Commons Attribution Non-Commercial License, which permits unrestricted non-commercial use, distribution, and reproduction in any medium, provided the original work is properly cited.

\begin{abstract}
Background: Center for Disease Control (CDC) recommends routine screening in all pregnant women at first visit for syphilis, HIV, Hepatitis B infection as they have high vertical transmission rate. Syphilis is brought to control by screening and early treatment with penicillin, whereas HIV and Hepatitis B are incurable viral infections till date. Hence prevention is the only way to control the disease in the population. The purpose of the study is to know the burden of sexually transmitted diseases, so that prevention programme is better planned.

Methods: This is a retrospective analytical study conducted from January 2005 to December 2014, in Karnataka Institute of Medical Sciences, Hubli, Karnataka. All the patients who delivered in septic ward, who were more than 28 weeks of gestation and who were HIV, HBsAg or VDRL positive were included in the study.

Results: Among the total of 79,472 deliveries, the prevalence of HIV, HBsAg and VDRL were 0.90, 1.06 and 0.31 respectively. There were 4 cases of co-infection. The prevalence of HIV was 0.79 in 2005 and reached its peak of 1.33 in 2008 and then showed a steady decrease, reaching a lowest of 0.52 in 2014. The prevalence of HBsAg was 0.70 in 2005 and reached a peak of 1.57 in 2014. The prevalence of VDRL was highest of 0.08 in 2005 and lowest of 0.02 in 2014. Highest operative deliveries were seen in HBsAg positive women. Stillbirths were maximum in VDRL positive women and least in HBsAg positive women. There were 9 maternal deaths in HIV positive women and 3 maternal deaths in HBsAg positive women.

Conclusions: In our study HIV prevalence is showing a down trend and syphilis is at the verge of elimination as seen globally. However prevalence of Hepatitis B has shown a rising trend over a decade in our institute, unlike a down trend seen globally. Intensifying the screening of Hepatitis B in pregnancy and Immunisation programme of neonates, reducing overcrowding and providing better living conditions, improving hygiene and health education should be done in order to reduce the prevalence of Hepatitis B infection.
\end{abstract}

Keywords: Syphilis, Hepatitis B, HIV, Vertical transmission, Maternal mortality

\section{INTRODUCTION}

Sexually transmitted diseases are relatively common in pregnancy. Center for Disease Control (CDC) recommends routine screening in all pregnant women at first visit for syphilis, HIV, Hepatitis B infection as they have high vertical transmission rate. Whereas other infections such as chlamydia, herpes simplex, Hepatitis $\mathrm{C}$, trichomoniasis, gonorrhoea, bacterial vaginosis are looked for whenever suspected or in high risk population. $^{1}$

In HIV vertical transmission to the fetus is around $30 \% .^{2}$ The vertical transmission occurs during antenatal, intrapartum and also during breastfeeding. Antiretroviral therapy during antenatal and intrapartum period, elective caesarean operation in selected cases and avoiding breastfeeding can bring down the vertical transmission rate to less than $2 \%$. In Hepatitis B infection, most of the 
vertical transmission (85\%) occurs in the peripartum period by ingestion of infected maternal fluid and only $15 \%$ transplacentally. ${ }^{3}$ Ten percent of infants born to women with acute HBV infection during the first trimester of pregnancy are $\mathrm{HBsAg}$-positive at birth and 80 to $90 \%$ of neonates become HBsAg-positive without prophylactic therapy if acute maternal infection develops during the third trimester of pregnancy. ${ }^{4}$ Prenatal treatment with nucleoside analogue for women with high viremia may improve the efficacy of neonatal immunoprohylaxis. Combination of HBIG (Hepatitis B Immunoglobulin) and Hepatitis B vaccination, reduces transmission rate to $3-7 \%$ when given no later than 12 hours after birth.

Syphilis at any stage in a pregnant women has an effect on the offspring. This effect depends upon the time of infection. First trimester abortions are relatively uncommon, but second trimester abortions do occur. It may result in premature delivery if the fetus is infected and also cause congenital syphilis in the new born. Risk of infection of the fetus during untreated early maternal syphilis is $75-95 \%$ decreasing to $35 \%$ approximately for maternal syphilis of more than 2 years. Treating with penicillin reduces the chance of vertical transmission. ${ }^{5}$ Syphilis is brought to control by screening and early treatment with penicillin, whereas HIV and Hepatitis B are incurable viral infections till date. Hence prevention is the only way to control the disease in the population. The purpose of the study is to know the burden of sexually transmitted diseases, which not only have maternal and peri-natal morbidity but also are a health hazard for the medical personnel, so that the purpose of screening these diseases in the population is reiterated and prevention programme is better planned, as antenatal mothers are the proxy of the disease in the population.

\section{Aims}

To find out the trend of sexually transmitted disease over a decade and to find out the prevalence, perinatal mortality and maternal mortality of HIV, Hepatitis B and Syphilis infected mothers delivered in KIMS, between January 2005 to December 2014.

\section{METHODS}

This is a retrospective analytical study conducted at our tertiary care centre from January 2005 to December 2014, in Karnataka Institute of Medical Sciences, Hubli, Karnataka. The case files of all the patients who underwent delivery in septic labour ward in KIMS, were taken from the medical records section and reviewed in detail. All the patients who delivered in septic ward, who were more than 28 weeks of gestation and who were HIV, HBsAg or VDRL positive were included in the study. The following parameters such as demography, prevalence, mode of delivery, maternal and perinatal morbidity and mortality rates were obtained.

\section{RESULTS}

Table 1: Age group of the infected women.

\begin{tabular}{|llll|}
\hline Age & HIV & HBsAg & VDRL \\
\hline$<20$ & 12 & 73 & 2 \\
\hline $20-30$ & 688 & 750 & 20 \\
\hline$>30$ & 4 & 52 & 4 \\
\hline
\end{tabular}

Table 2: Year wise distribution of STD deliveries.

\begin{tabular}{|llllllll|}
\hline Year & Total deliveries & HIV & HIV prevalence & HBsAg & $\begin{array}{l}\text { HBSAg } \\
\text { prevalence }\end{array}$ & Syphilis & Syphilis prevalence \\
\hline 2005 & 5651 & 45 & 0.79 & 40 & 0.70 & 5 & 0.08 \\
\hline 2006 & 6421 & 65 & 1.01 & 52 & 0.80 & 1 & 0.01 \\
\hline 2007 & 6990 & 82 & 1.17 & 55 & 0.70 & 2 & 0.03 \\
\hline 2008 & 7253 & 97 & 1.33 & 63 & 0.86 & 4 & 0.01 \\
\hline 2009 & 8160 & 91 & 1.11 & 72 & 0.88 & 4 & 0.04 \\
\hline 2010 & 8563 & 93 & 1.08 & 85 & 0.94 & 2 & 0.02 \\
\hline 2011 & 8610 & 67 & 0.77 & 95 & 1.10 & 3 & 0.03 \\
\hline 2012 & 8652 & 57 & 0.65 & 113 & 1.53 & 2 & 0.02 \\
\hline 2013 & 9532 & 56 & 0.58 & 148 & 1.55 & 2 & 0.02 \\
\hline 2014 & 9640 & 51 & 0.52 & 152 & 1.57 & 26 & 0.31 \\
\hline Total & 79,472 & 704 & 0.90 & 875 & 1.06 & & \\
\hline
\end{tabular}

There were 79,472 deliveries in the study period. Among these the prevalence of HIV, HBsAg and VDRL were $0.90,1.06$ and 0.31 respectively. There were 4 cases of co-infection ( 3 cases of $\mathrm{HIV}+\mathrm{HBsAg}$ and 1 case of
HBsAg +VDRL). The age group distribution of infected women is given in Table 1. Maximum number of infected women was seen in the age group of 20 to 30years. The year wise cases of STD's and their prevalence are shown 
in Table 2. The prevalence of HIV was 0.79 in 2005 and reached its peak of 1.33 in 2008 and then showed a steady decrease, reaching a lowest of 0.52 in 2014. The prevalence of $\mathrm{HBsAg}$ was 0.70 in 2005 and reached a peak of 1.57 in 2014. The prevalence of VDRL was highest of 0.08 in 2005 and lowest of 0.02 in 2014. This rising trend of Hepatitis and downward trend of HIV is seen in Figure 1. Table 3, shows the mode of delivery in the infected women, with highest operative deliveries seen in HBsAg positive women. Stillbirths were maximum in VDRL positive women and least in $\mathrm{HBsAg}$ positive women as shown in Table 4 . There were 9 maternal deaths in HIV positive women and 3 maternal deaths in $\mathrm{HBsAg}$ positive women.

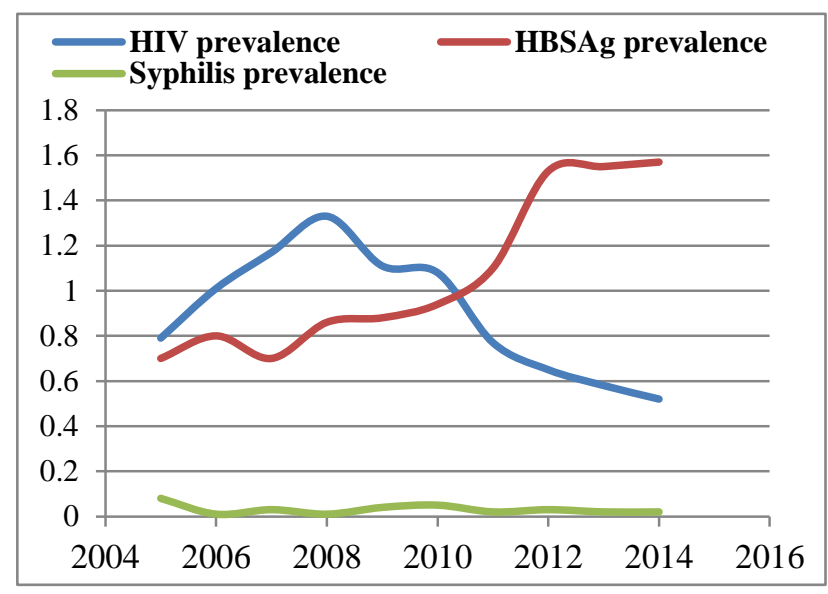

Figure 1: Line diagram of prevalence of STD's showing the trend over a decade.

Table 3: Mode of delivery in the infected women.

\begin{tabular}{|llll|}
\hline STD's & Vaginal & Forceps & $\begin{array}{l}\text { Caesarean } \\
\text { operation }\end{array}$ \\
\hline HIV & $570(80.96 \%)$ & $14(1.98 \%)$ & $120(17.04 \%)$ \\
\hline HBsAg & $661(75.54 \%)$ & $28(3.2 \%)$ & $186(21.25 \%)$ \\
\hline VDRL & $26(100 \%)$ & $0(0 \%)$ & $0(0 \%)$ \\
\hline
\end{tabular}

Table 4: Maternal and Perinatal mortality.

\begin{tabular}{|lll|}
\hline STD's & Stillbirths & Maternal mortality \\
\hline HIV & $65(9.23 \%)$ & $9(1.2 \%)$ \\
\hline HBsAg & $51(5.82 \%)$ & $3(0.34 \%)$ \\
\hline VDRL & $7(26.92 \%)$ & $0(0 \%)$ \\
\hline
\end{tabular}

\section{DISCUSSION}

In our study of ten years the prevalence of prevalence of HIV, HBsAg and VDRL were 0.90, 1.06 and 0.31 respectively. Similar study was done by Mehta KD et al, in 2012 which showed seropositivity of Hepatitis B was $2.9 \%$, hepatitis C was $0.19 \%$, syphilis was $0.48 \%$, and HIV was $0.38 \%$. Out of the 1038 samples, no coinfection was found between hepatitis $B$, hepatitis $C$, syphilis, or HIV. ${ }^{6}$ Another study done by Khokar N et al showed that Seropositivity of HBV (3.03\%), HCV
(0.19\%), syphilis $(0.49 \%)$, and HIV was $0.39 \%$. Coinfection with syphilis and HIV was found in $(0.29 \%)$ of patients. ${ }^{7}$ Both the study show high HBsAg prevalence and low VDRL prevalence when compared to HIV similar to our study. In our study the prevalence of HIV was 0.79 in 2005 and reached its peak of 1.33 in 2008 and then showed a steady decrease, reaching a lowest of 0.52 in 2014. According to the UNAIDS GAP report 2014, there is a declining trend of HIV across the globe, with a decline in number of people with newly detected HIV. In 2001, there were 3.4 million [3.3 million-3.6 million] new infections, where as in 2013, there were 2.1 million [1.9 million-2.4 million] new HIV infections, showing a decline of $38 \%$. Around 900000 new HIV infections among children since 2009 were prevented by providing antiretroviral medicines for pregnant women living with HIV. ${ }^{8}$ According to NACO Annual report 2012-13, India has the $3^{\text {rd }}$ largest HIV epidemic in the world and overall India's HIV epidemic is slowing down, with $57 \%$ decline in new HIV infection between 2000 and 2011. ${ }^{9}$ According to the NACO Annual report 201415 , the national HIV prevalence in ANC is $0.35 \%$ and $0.53 \%$ in Karnataka, standing fifth position in the nation. Highest Prevalance was recorded in Nagaland $(0.88 \%)$, followed by Mizoram $(0.68 \%)$, Manipur $(0.64 \%){ }^{10}$ According to our study prevalence of HIV in our institute was $0.52 \%$ which was similar to prevalence of Karnataka.

Across the globe, the prevalence of chronic hepatitis B infection is variable, ranging from $<1 \%$ in low endemic areas and up to $30 \%$ in highly endemic areas. There has been an overall decline in the prevalence of the disease due to global infant and childhood vaccination programs. ${ }^{11}$ Asia has the highest number of HBsAg carriers, followed by Africa. In Asia the most common form of transmission is perinatal transmission, whereas horizontal transmission in childhood is thought to be the predoimant mode of transmission in Africa. The prevalence of Hepatitis B in India is $4 \%$ with 36 million carriers. ${ }^{12}$ Within the country variable prevalence of Hepatitis B is seen from north to south, the lowest prevalence is $2.3 \%$ in a large cohort of 20,000 blood donors in northern India. ${ }^{13}$ The highest prevalence rate is $5.7 \%$ in a community based study in almost 2000 people from southern India. ${ }^{14}$ According to our study prevalence in 2014 is $1.57 \%$ and it has seen an increasing trend over a decade from $2005(0.7 \%)$.

According to WHO estimate in 2012, about a million pregnant women were infected with active syphilis globally and in India, about 103960 pregnant women were infected with syphilis making the prevalence $0.38 \%$. $^{15}$ According to CDC, the rate of syphilis initially declined to $89.7 \%$ during 1990-2000, and then increased annually during 2001-2009 before decreasing in 2010 and remaining unchanged during 2011. The rate again increased during 2012 and $2013 .^{16}$ In the Indian scenario, programme data from National AIDS Control Organization (NACO) shows a declining trend of seropositivity of syphilis (as defined as being rapid 
plasma reagin $[\mathrm{RPR}] /$ venereal disease research laboratory [VDRL] positive) among antenatal clinic (ANC) attendees at Designated STI/RTI clinics (DSRCs), from $1.7 \%$ in $2005-2006$ to $0.8 \%$ since $2010-2011 .^{15}$ In 2007 , WHO launched global initiative to eliminate congenital syphilis and in 2011 dual elimination of HIV and Syphilis were launched. However in India, a national strategy "toward elimination of parent-to child transmission (EPTCT) of syphilis" was launched in February 2015 by NACO under Ministry of Health and Family Welfare and World Health Organization (WHO). This strategy emphasizes the management of syphilis among pregnant women through a functional convergence approach. The goal of the strategy is to eliminate parent to child transmission E-PTCT of syphilis by 2017. It targets to reduce the incidence of congenital syphilis to $<0.3$ cases/1000 live births by 2017 . The program targets to achieve the above goal are: ANC coverage (pregnant women having at least one ANC visit) of $\geq 95 \%$, covering of syphilis testing of ANC attendees of $\geq 95 \%$ and treatment of syphilis-reactive ANC attendees of $\geq 95 \%$. ${ }^{17}$ However in our study, prevalence of syphilis has always remained less than $0.1 \%$, and has been fluctuating between $0.01 \%$ to a highest of $0.08 \%$. This is far less than the National prevalence of syphilis and this can be explained with a fact that it is a curable disease and in our study, we have tried to find out the prevalence of syphilis among the labouring patients only.

\section{CONCLUSIONS}

In our study HIV prevalence is showing a down trend and syphilis is at the verge of elimination as seen globally. However prevalence of Hepatitis B has shown a rising trend over a decade in our institute, unlike a down trend seen globally. Intensifying the screening of Hepatitis B in pregnancy and Immunisation programme of neonates, reducing overcrowding and providing better living conditions, improving hygiene and health education should be done in order to reduce the prevalence of Hepatitis B infection.

\section{Funding: No funding sources}

Conflict of interest: None declared

Ethical approval: The study was approved by the Institutional Ethics Committee

\section{REFERENCES}

1. Sexually transmitted diseases during Pregnancy CDC Fact Sheet. http://www.cdc.gov/ std/ pregnancy/stdfact-pregnancy.htm

2. Mudaliar AL, Menon MKK. Clinical Obstetrics, 11th ed. Hyderabad, India. Universities Press (India) Private Limited. 2011.

3. Okada K, Kamiyama I, Inomata $\mathbf{M}$, Imai $\mathbf{M}$, Miyakawa Y. E antigen and anti-e in the serum of asymptomatic carrier mothers as indicators of positive and negative transmission of hepatitis B virus to their infants. N Engl J Med. 1976;294:746-9.

4. Sweet RL. Hepatitis B infection in pregnancy. Obstet. Gynecol. Report. 1990;2:128.

5. Sexually Transmitted Diseases. Data \& Statistics2013 Sexually Transmitted Diseases Surveillance National Profile. http://www.cdc.gov/ std/ stats13/syphilis.htm

6. Mehta KD, Antala S, Mistry M, Goswami Y. Seropositivity of hepatitis B, hepatitis C, syphilis, and HIV in antenatal women in India. J Infect Dev Ctries. 2013;7(11):832-7.

7. Khokhar N, Jethwa D, Lunagaria R, Panchal N, Badrakiya S, Badrakiya G. Seroprevalence of Hepatitis B, Hepatitis C, Syphilis and HIV in Pregnant Women in a Tertiary Care Hospital, Gujarat, India. International Journal of Current Microbiology and applied sciences. ISSN: 23197706. 2015;4(9):188-94. http://www.ijcmas.com

8. The Gap Report-Un Aids. www.unaids.org /.../unaids/.../unaidspublication/.../UNAIDS_Gap_rep ort. 2014.

9. NACO annual report. www.naco.gov.in/ .../Annual\%20Report/Annual\%20report \% 2012-13.

10. NACO annual report 2014-15. www.naco.gov.in/ NACO/.../Annual_Report/NACO_Annual_Report/A nn.

11. Hwang EW. Ramsey Cheung: Global Epidemiology of Hepatitis B Virus (HBV) Infection. N A J Med Sci. 2011;4(1):7-13.

12. Tandon BN, Acharya SK, Tandon A. Epidemiology of hepatitis B virus infection in India. Gut. 1996;38(2):S56-9.

13. Behal R, Jain R, Behal KK. Seroprevalence and risk factors for hepatitis B virus infection among general population in northern India. Arq Gastroenterol. 2008;45(2):137-40.

14. Kurien T, Thyagarajan SP, Jeyaseelan L. Community prevalence of hepatitis B infection \& modes of transmission in Tamil Nadu, India. India $\mathbf{J}$ Med Res. 2005;121(5):670-5.

15. Marfatia YS, Pandya I, Jose SK. Congenital syphilis. Marching toward elimination. Indian J Sex Transm Dis. 2015;36(1):1-2.

16. Sexually Transmitted Diseases Data \& Statistics 2013 Sexually Transmitted Diseases Surveillance National Profile. www.cdc.gov/std/ stats13/ syphilis.htm

17. The national strategy and operational guidelines towards elimination of congenital syphilis. New Delhi: NACO, MoHFW, Government of India. 2015.

Cite this article as: Mahadevappa K, Prasanna N, Antaratani RC. Sexually transmitted diseases in laboring women: trend over a decade. Int J Reprod Contracept Obstet Gynecol 2016;5:743-6. 